\title{
IMPACT OF REAL AND REACTIVE POWER CONTROLLABILITY OF STATCOM ON TRANSMISSION LINE PROTECTION
}

\author{
H.V. Gururaja Rao \\ E\&E Department, Manipal Institute of Technology, MAHE, Manipal, India \\ Dr. Nagesh Prabhu \\ E\&E Department, NMAM Institute of Technology, Nitte, India \\ R.C. Mala \\ E\&E Department, Manipal Institute of Technology, MAHE, Manipal, India
}

\begin{abstract}
Static synchronous Compensator (STATCOM) is a shunt connected Voltage Source Converter (VSC) based FACTS controller which is useful in improving the voltage regulation. VSC based FACTS controllers facilitate connection of energy storage devices like battery, fuel cell, Super Magnetic Energy Storage(SMES) etc. at the DC bus. Addition of energy storage device results in better real and reactive power flow control, transient stability enhancement and power oscillation damping. However, FACTS controllers with energy storage device in the line poses new challenges for the line protection device. Operating region of STATCOM with energy storage device (STATCOM - ES) encompasses all the four quadrants in $P-Q$ plane. Impedance contribution by STATCOM operating in any of these four quadrants can modify apparent impedance seen by distance relay and hence needs to be investigated thoroughly. Main aim of this paper is to analyze the impact of emulated conductance and susceptance by four quadrant operation of STATCOM on the performance of distance relay in a hybrid compensated system. A novel control strategy to dynamically modify the reference for real power exchange by STATCOM is proposed to avoid damage to the STATCOM during fault. Possibilities of distance relay under reach and over reach due to operation of STATCOM - ES in various operating modes and impact of fault resistance on the relay performance is discussed.
\end{abstract}

Keywords: Distance relay, Emulated conductance and susceptance, Energy storage, STATCOM

Cite this Article: H.V. Gururaja Rao, Dr. Nagesh Prabhu, R.C. Mala, Impact of Real and Reactive Power Controllability of STATCOM on Transmission Line Protection, International Journal of Electrical Engineering \& Technology, 10(3), 2019, pp. 21-35. http://iaeme.com/Home/issue/IJEET?Volume=10\&Issue=3 


\section{INTRODUCTION}

In order to improve transient stability of the system during system disturbance, sufficient stability margin is necessary. Hence transmission lines are often underutilized. By employing FACTS controllers in the lines, power transfer through the lines can be enhanced up to the thermal limit and the transient stability limit can be increased [1,2]. Long transmission lines generally require both series and shunt compensation to regulate power through the line and to provide voltage support. For economic reasons, series compensation is provided by a passive capacitor and shunt compensation by a static synchronous compensator, STATCOM [3]. However, operation and control of FACTS controllers modify power system parameters during steady state and transient disturbance. Long transmissions are generally protected by distance protection schemes [4]. Emulated impedance by a FACTS controller modifies the apparent impedance seen by a distance relay and hence needs to be properly investigated. Protection of transmission lines in the presence of series FACTS controllers is studied in $[5,6]$. Impact of shunt connected FACTS controllers, SVC and STATCOM on the operation of the distance relay is discussed in $[7,8,9,10]$. Adaptive distance protection to minimize the mal operation of the relay for lines compensated with SSSC, STATCOM and UPFC is reported in $[11,12,13]$. However, impact of emulated conductance and susceptance by STATCOM under different operating modes and impact of adding an energy storage device to the DC bus of FACTS controller on distance relay performance is not discussed by these authors. Addition of energy storage device facilitates exchange of real power with the network and hence further improves control of real and reactive power flow through the line [14]. A STATCOM without energy storage device injects a current which is close to $\pm 90^{\circ}$ with the STATCOM bus voltage. In the case of a STATCOM with an energy storage device, angle of injected current can be any angle between $0^{\circ}$ and $360^{\circ}$ with STATCOM bus voltage. Hence the impact of incorporating an energy storage device at the DC bus of a FACTS controller needs to be thoroughly investigated. Very little work is reported regarding the effect of FACTS controllers with energy storage device on power system performance. In [15, 16], modification in steady state characteristics of SSSC and STATCOM when energy storage device is integrated with them is discussed. Authors do not discuss about its impact on the system performance. Enhancement of transient stability of the system when a fuel cell is used with STATCOM is highlighted in [17]. Effect of integrating an SMES with SSSC and UPFC on distance relay performance is discussed in $[18,19]$. DQ model of a STATCOM with energy storage device and its effectiveness in mitigating sub synchronous Resonance (SSR) is presented in [20]. However, emulated impedance by SSSC and UPFC during various operating modes under normal and fault condition is not highlighted and impact of STATCOM with energy storage device on distance relay performance is not reported. Also a suitable control strategy for a STATCOM to avoid damage to STATCOM during fault is not discussed by any of these authors. The main objective of this paper is to compute and analyze the impact of emulated conductance and susceptance by four quadrant operation of STATCOM - ES on the distance relay performance Also a novel control strategy is proposed for real power controller of STATCOM to prevent damage caused to it during fault.

\section{SYSTEM MODEL}

\subsection{Test system}

Fig. 1 shows a single machine connected to infinite bus through a hybrid compensated line with STATCOM - ES at the middle of the line. $\mathrm{V}_{\mathrm{g}} \angle \theta \mathrm{g}, \mathrm{V}_{\mathrm{s}} \angle \theta \mathrm{s}$ and $\mathrm{E}_{\mathrm{b}} \angle 0$ represent generator terminal voltage, STATCOM bus voltage and the voltage at the infinite bus respectively. $R_{t}$ and $X_{t}$ are the transformer resistance and reactance respectively. $R_{L}\left(R_{1}+R_{2}\right)$ and $\mathrm{X}_{\mathrm{L}}\left(\mathrm{X}_{1}+\mathrm{X}_{2}\right)$ represent respectively the resistance and reactance of the line. $\mathrm{R}_{\mathrm{S}}$ is the 
resistance and $\mathrm{X}_{\mathrm{S}}$ reactance of converter transformer. $\mathrm{X}_{\mathrm{SYS}}$ is the system reactance on the infinite bus side.

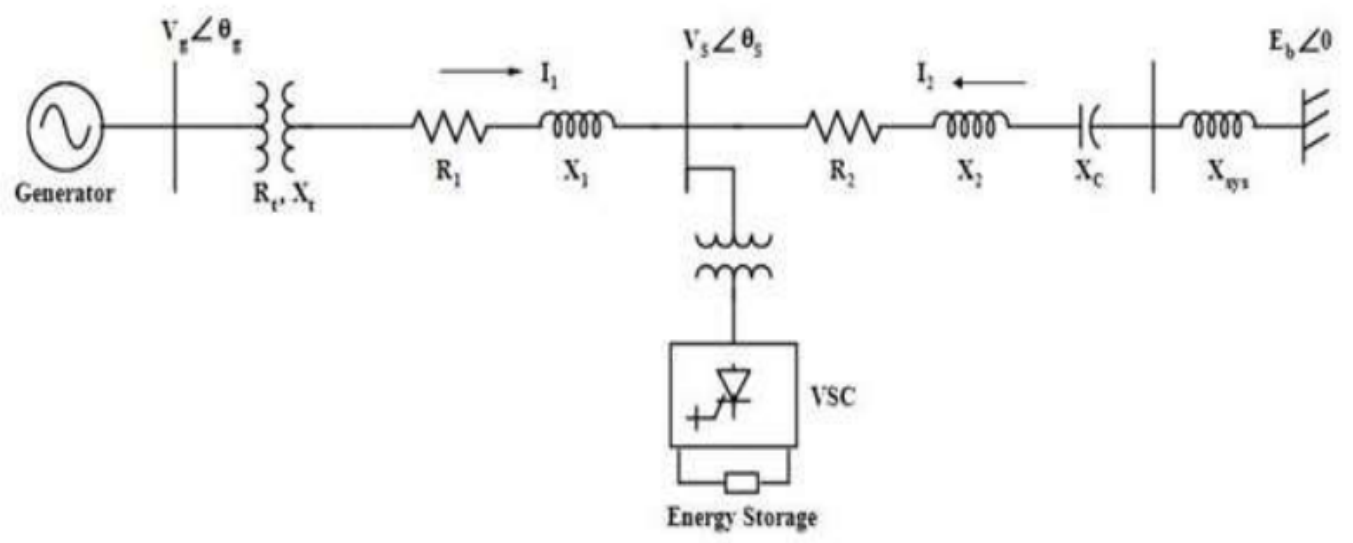

Figure 1 Electrical system

\subsection{System Equations}

A DQ model of STATCOM with energy storage device is employed for the analysis. A three level, twelve pulse converter is used for STATCOM. In D-Q frame of reference, the converter output voltage is given by,

$V_{S}^{i}=\sqrt{V_{S Q}^{i}{ }^{2}+V_{S D}^{i}}$

where,$V_{s D}^{i}=K_{m} * V_{d c} * \operatorname{Sin}\left(\theta_{s}+\alpha\right)$

$V_{s Q}^{i}=K_{m} * V_{d c} * \operatorname{Cos}\left(\theta_{s}+\alpha\right)$

Where $\mathrm{K}_{\mathrm{m}}=\mathrm{K}^{*} \cos \beta ; \mathrm{K}=\frac{2 \sqrt{6}}{\pi}$ for a 12 pulse converter and ' $\theta_{s}$ 'is the angle of STATCOM bus voltage.

$$
\theta_{s}=\tan ^{-1}\left(\frac{v_{s D}}{v_{s Q}}\right)
$$

Magnitude of STATCOM bus voltage,

$V_{S}=\sqrt{V_{S Q}^{2}+V_{S D}^{2}}$

STATCOM equations in D-Q variables are given by

$\frac{d i_{S D}}{d t}=-\frac{R_{S} \omega_{B}}{X_{S}} i_{S D}-\omega_{0} i_{S Q}+\frac{\omega_{B}}{X_{S}}\left[v_{S D}-v_{S D}^{i}\right]$

$\frac{d i_{S Q}}{d t}=-\frac{R_{S} \omega_{B}}{X_{S}} i_{S Q}+\omega_{0} i_{S D}+\frac{\omega_{B}}{X_{S}}\left[v_{S Q}-v_{S Q}^{i}\right]$

Real and reactive currents injected by STATCOM-ES is given by

$I_{P}=I_{S D} \operatorname{Sin} \theta+I_{S Q} \operatorname{Cos} \theta$

$I_{R}=-I_{S D} \cos \theta+I_{S Q} \operatorname{Sin} \theta$

Here ' $\theta$ ' is the angle of STATCOM current.

It should be noted that, positive $\mathrm{I}_{\mathrm{P}}$ implies STATCOM - ES drawing real power and positive $I_{R}$ specifies inductive mode of operation of STATCOM - ES.

Active and reactive power of STATCOM - ES are given by 


$$
\begin{aligned}
& P s=I s D * V s D+I s Q * V s Q \\
& P_{s}=I_{s Q} * V_{s D}^{i}-I_{s D} * V_{s Q}^{i}
\end{aligned}
$$

\subsection{Control strategy for STATCOM}

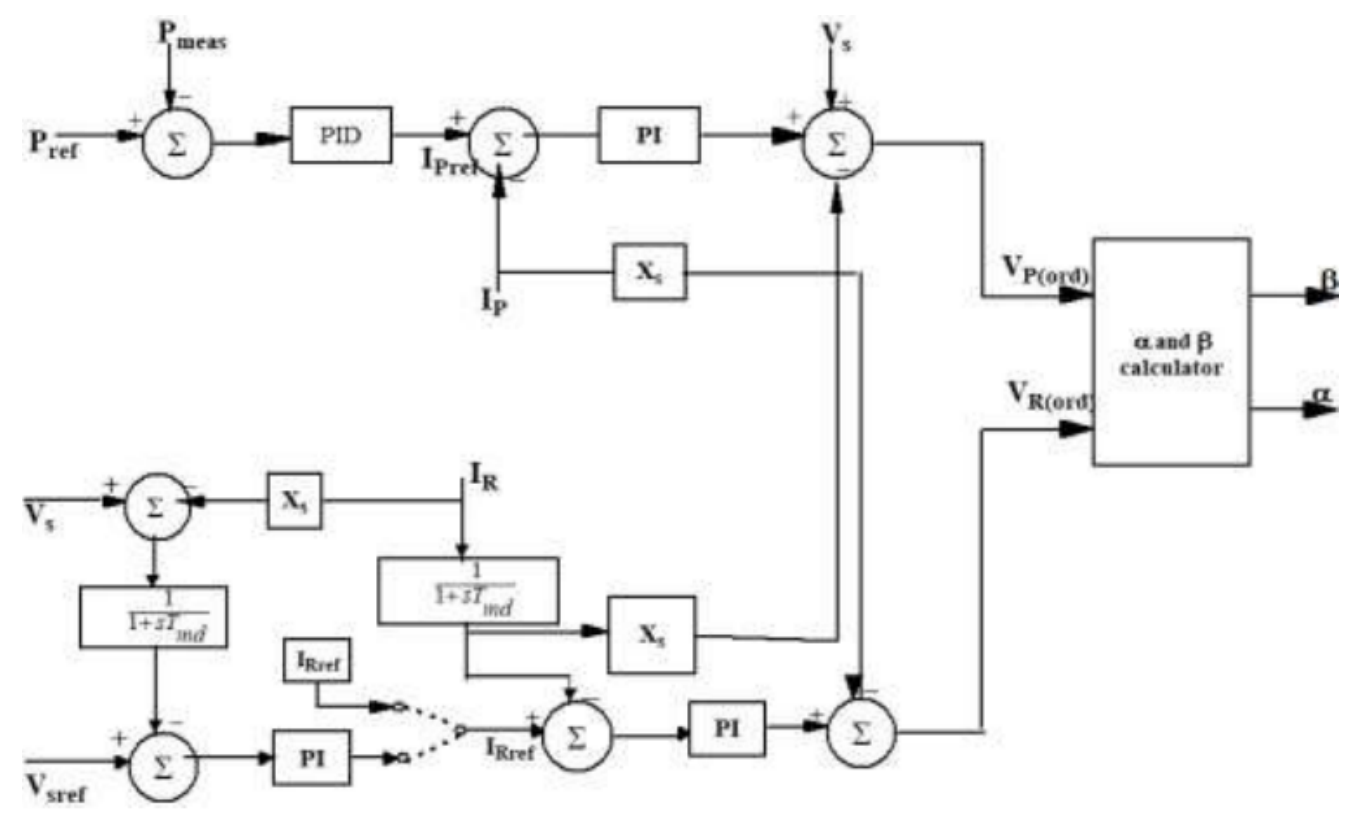

Figure 2 Control strategy for STATCOM- ES

Type 1 controller is used for the STATCOM in the present work. In the case of Type 1 controller, exchange of real power with the network can be controlled by phase angle ' $\alpha$ ' and reactive power exchange can be controlled by regulating the magnitude of converter output voltage as a function of dead angle ' $\beta$ '. Fig. 2 shows the Type 1 controller used for STATCOM. Reference for real current is obtained through power controller of STATCOM. Reference for reactive current of STATCOM can be kept constant or can be controlled to keep the magnitude of the STATCOM bus voltage at the preferred value. Positive ' $\mathrm{P}_{\text {ref }}$ ' signifies STATCOM - ES drawing active power from the network and negative $\mathrm{P}_{\text {ref }}$ implies STATCOM - ES supplying active power to the network.

Required values of ' $\alpha$ ' and ' $\beta$ ' are calculated using equations 12 and 13.

$$
\begin{aligned}
& \alpha=\tan ^{-1}\left(\frac{V_{R(\text { ord })}}{V_{P(\text { ord })}}\right) \\
& \beta=\operatorname{Cos}^{-1}\left(\frac{\sqrt{V_{P(\text { ord })}^{2}+V_{R(\text { ord })}^{2}}}{k * V_{d c}}\right)
\end{aligned}
$$

\section{METHODOLOGY}

A 150MVA STATCOM is considered for the analysis. With a Base MVA of 892.4MVA, and assuming STATCOM bus voltage as 1pu, rated current (magnitude) of STATCOM is 0.1681 pu. In the various case studies considered in this work, to study the impact of STATCOM ES on distance relay, the real and reactive power exchange by STATCOM are so selected that STATCOM will be operating close to its rated capacity.

Presence of DC component in fault current and voltage signals will result in errors in the measurement of fundamental component of voltage and current signals using DFT. This might lead to mal operation of distance relay. Hence a digital mimic impedance filter is used 
to remove the DC offset. DFT algorithm is used to determine the positive sequence fundamental components of voltage and current. Apparent impedance seen by distance relay is computed by taking the ratio of appropriate voltage and current.

\section{RESULTS AND DISCUSSION}

Test system shown in Fig. 1 is modelled in Matlab/Simulink. Initial conditions are obtained by Newton Raphson iterative technique. Generator power output is taken as 0.9pu. Reactance compensation provided by the series capacitor is fixed at $0.45 \mathrm{pu}$. Voltage at the DC side of STATCOM is assumed to be maintained constant by the energy storage device and is taken as $0.7 \mathrm{pu}$.

\subsection{Impact of STATCOM under normal (no fault) condition}

Under normal condition, equations 14 to 18 are used to compute theoretically the emulated conductance \& susceptance by STATCOM impedance measured by relay and impedance between relay location and infinite bus.

Admittance emulated by STATCOM,

$Y_{S T A T}=G_{S T}+j B_{S T}=\frac{I_{P}-j I_{R}}{\left|V_{S}\right|}=\frac{\overrightarrow{V_{S}}}{\overrightarrow{I_{S}}}$

Impedance between relay location and STATCOM,

$Z_{L 1 L}=\frac{\overrightarrow{V_{1}}-\overrightarrow{V_{S}}}{\overrightarrow{I_{1}}}=0.5 * Z_{L 1}=R_{1}+j X_{1}$

Apparent impedance seen by relay,

$Z_{\text {Relay }}=\frac{V_{1}}{I_{1}}=Z_{L 1 L}+\frac{V_{S}}{I_{1}}$

Impedance between STATCOM and infinite bus,

$Z_{R 1}=R_{2}+j X_{2}+j X_{S Y S}-j X_{C}$

Impedance between relay location and infinite bus,

$Z_{R I B}=Z_{L 1 L}+\frac{Z_{S T A T} * Z_{R 1}}{Z_{S T A T}+Z_{R 1}}$

Analysis is carried out under the following operating modes of STATCOM - ES.

Case 1: No STATCOM; Case 2: Capacitive mode $(\mathrm{Qs}=-0.16248$, Pref $=0)$

Case 3: Inductive mode $(\mathrm{Qs}=0.1569$, Pref $=0)$; Case 4: Absorbing real power $(\mathrm{Qs}=0$, Pref $=0.15)$; Case 5: Supplying real power $(\mathrm{Qs}=0$, Pref $=0.15)$; Case 6: Operation in first quadrant (capacitive mode, absorbing real power, Qs $=-0.11094$, Pref $=0.1$ );

Case 7: Operation in third quadrant (Inductive mode, supplying real power, Qs $=0.11094$, Pref $=-0.1$ )

Table 1 shows the emulated conductance $\left(\mathrm{G}_{\mathrm{ST}}\right)$ and susceptance $\left(\mathrm{B}_{\mathrm{ST}}\right)$ by STATCOM $\mathrm{ES}$, and impedance measured by the distance relay, $\mathrm{Z}_{\text {Relay }}$ and $\mathrm{Z}_{\mathrm{RIB}}$ under these operating modes. 
Table 1. Normal condition

\begin{tabular}{|c|c|c|c|}
\hline $\begin{array}{c}\text { Operating } \\
\text { condition }\end{array}$ & $\mathbf{Y}_{\text {STAT }}$ & $\mathbf{Z}_{\text {RIB }}$ & $\mathbf{Z}_{\text {Relay }}$ \\
\hline Case 1 & $0+\mathrm{j} \mathrm{0}$ & $0.04002+\mathrm{j} 0.61$ & $1.008+\mathrm{j} \quad 0.1823$ \\
\hline Case 2 & $1.8^{*} 10^{-3}+\mathrm{j} 0.16418$ & $0.04128+\mathrm{j} 0.611$ & $1.0287+\mathrm{j} 0.16141$ \\
\hline Case 3 & $2^{*} 10^{-3}-\mathrm{j} 0.1679$ & $0.0389+\mathrm{j} 0.608$ & $0.986+\mathrm{j} 0.202$ \\
\hline Case 4 & $0.15722+\mathrm{j}$ & $0.041231+\mathrm{j}$ & $1.0139+\mathrm{j} 0.183$ \\
& 0.00014254 & 0.60885 & \\
\hline Case 5 & $-0.15483-\mathrm{j}$ & $0.03864+\mathrm{j} 0.61103$ & $1.0019+\mathrm{j} 0.18149$ \\
\hline Case 6 & 0.0014724 & & \\
\hline Case 7 & $0.10275+\mathrm{j}$ & $0.041728+\mathrm{j}$ & $1.0263+\mathrm{j} 0.16882$ \\
& 0.11344 & 0.61013 & \\
\hline & $0.10406-\mathrm{j}$ & $0.038372+\mathrm{j}$ & $0.98897+\mathrm{j} 0.19563$ \\
\hline
\end{tabular}

It can be observed from Table 1 that when STATCOM - ES exchanges reactive power alone, $\mathrm{G}_{\mathrm{ST}}$ is small positive (to meet losses). $\mathrm{B}_{\mathrm{ST}}$ is negative in inductive mode of operation and positive in capacitive mode of operation. It is interesting to note that positive $\mathrm{B}_{\mathrm{ST}}$ increases the resistance measured by relay and it decreases the reactance seen by the distance relay. Similarly, negative $B_{S T}$ decreases the resistance seen by the distance relay and it increases the reactance measured by the distance relay. Similarly, STATCOM - ES emulates a large positive conductance $\left(\mathrm{G}_{\mathrm{ST}}\right)$ while absorbing real power and a large negative conductance while supplying real power. It is interesting to note that positive $\mathrm{G}_{\mathrm{ST}}$ increases the resistance and reactance measured by the distance relay. Similarly, negative value of $\mathrm{G}_{\mathrm{ST}}$ decreases the resistance and reactance measured by the distance relay. It can also be observed from table 1 that in first quadrant operation of STATCOM, resistance measured by the distance relay is increased and reactance measured is decreased. In third quadrant of operation of STATCOM, resistance measured by the distance relay is decreased and reactance measured is increased.

A distance relay with quadrilateral characteristics is considered for analysis. Directional quadrilateral relay with a directional angle of $-15^{\circ}$ and a negative restrain angle of $115^{\circ}$ is used. Also a fault impedance of $15 \Omega(0.0455 \mathrm{pu})$ is included in the relay setting. Zone 1 range of relay operation is assumed to cover $80 \%$ of line length. All further analysis is carried out with respect to zone 1 relay operation (for the relay at the machine end). Fig.3 gives the impedance seen by the relay in $\mathrm{R}-\mathrm{X}$ plane for capacitive and inductive mode of operation of STATCOM - ES. Fig. 4 shows the impedance measured by the distance relay on R - X plane while STATCOM - ES absorbs real power / supplies real power.

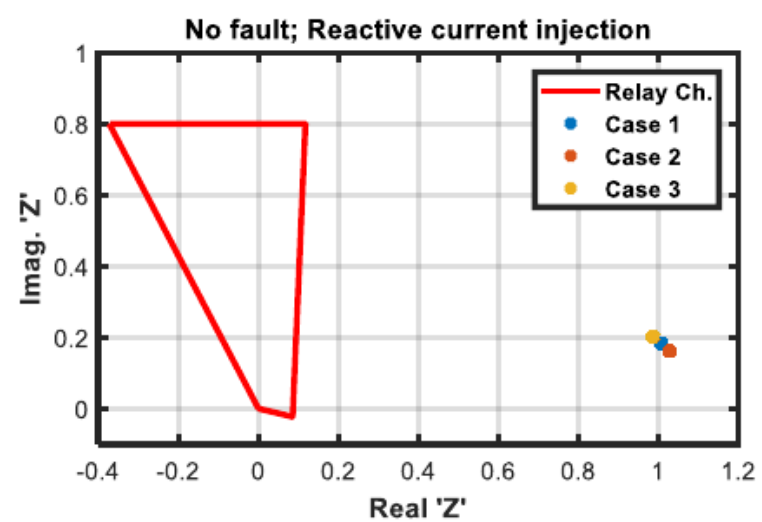

Figure 3 ZRelay, reactive current injection

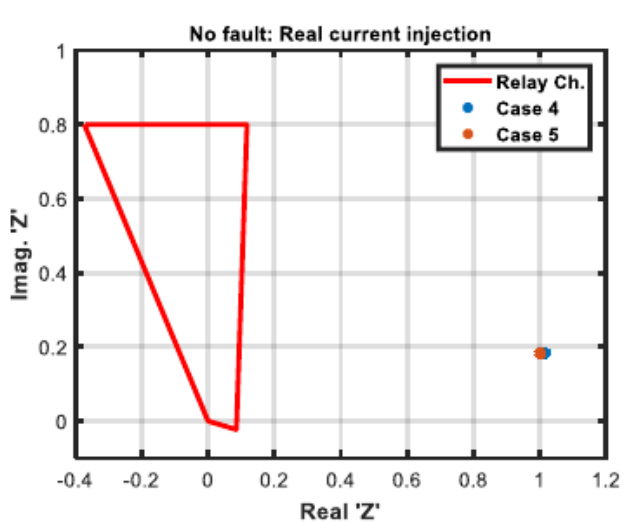

Figure 4. ZRelay, real current injection 
Fig. 5 shows the plot of impedance seen by relay on R - X plane while STATCOM - ES simultaneously injects real and reactive current. It is very clear from Fig.3,4 and 5 that irrespective of the operating mode of STATCOM - ES, the distance relay does not operate under normal condition, when STATCOM is operated with in its rated capacity.

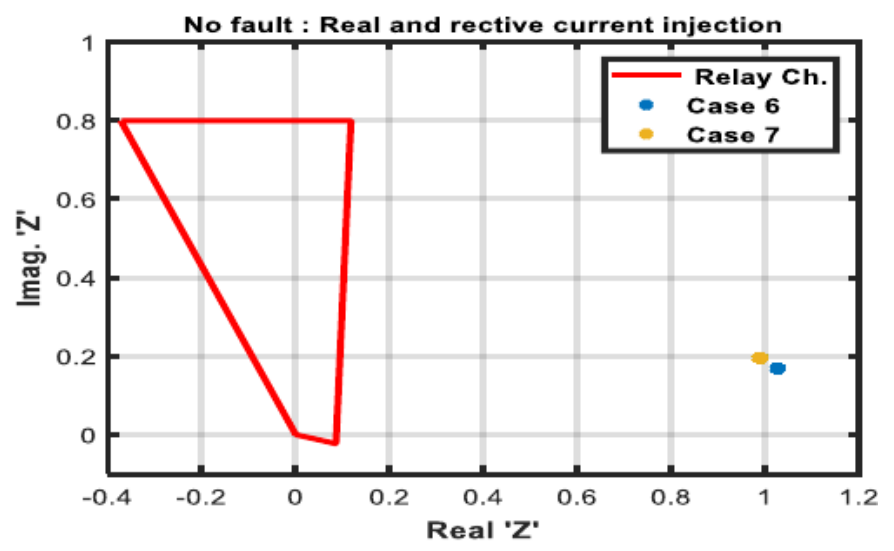

Figure $5 \mathrm{Z}_{\text {Relay, }}$ Simultaneous real and reactive current injection

\subsection{Impact of STATCOM - ES on distance relay operation during fault}

\subsubsection{Control strategy for STATCOM - ES during fault}

During short circuit faults, line current increases and hence magnitude of STATCOM bus voltage $\left(\mathrm{V}_{\mathrm{s}}\right)$ decreases drastically. It is observed that $\mathrm{V}_{\mathrm{s}}$ reduces to as low as $0.3 \mathrm{pu}$, depending on the fault type and fault location. Hence, STATCOM bus voltage cannot be maintained at the pre fault value during fault. Reactive current of STATCOM, $I_{R}$, is hence held constant during fault, at the prefault value. When STATCOM is exchanging real power with the network, with a low STATCOM bus voltage, it is found through various case studies that; IP must be increased to as high as 3 to 4 times the rated current of STATCOM, during fault, to maintain real power exchange constant (at the prefault value). Flow of such high current even for a small duration during fault will damage the STATCOM components. Hence, to avoid the damage to STATCOM during fault due to excessive currents, reference value for real power controller (Pref) is dynamically changed as per equation 19. Please note that in equation $19, \mathrm{~V}_{\mathrm{sm}}$ is the measured value of STATCOM bus voltage and $\mathrm{I}_{\mathrm{P}}$ is the prefault value of real current injected by STATCOM. It is observed that, with this control strategy, real current and hence the total current injected by STATCOM is well within its ratings even during fault and thus no damage will be caused to STATCOM.

$$
P_{\text {ref }}=V_{s m} * I_{P}
$$

\subsubsection{STATCOM outside fault loop}

In the system considered for analysis, STATCOM - ES is installed at the center of the line. Hence for bolted faults up to 50\%-line length, STATCOM - ES will not be in the fault loop. Thus for a fault on the line at a distance ' $x$ ' pu from the relay location $(0<x \leq 0.5)$, equation 20 is used to compute the impedance seen by the distance relay.

$$
Z_{\text {Relay }}=x * Z_{L 1}
$$


Table 2. Fault at $25 \%$

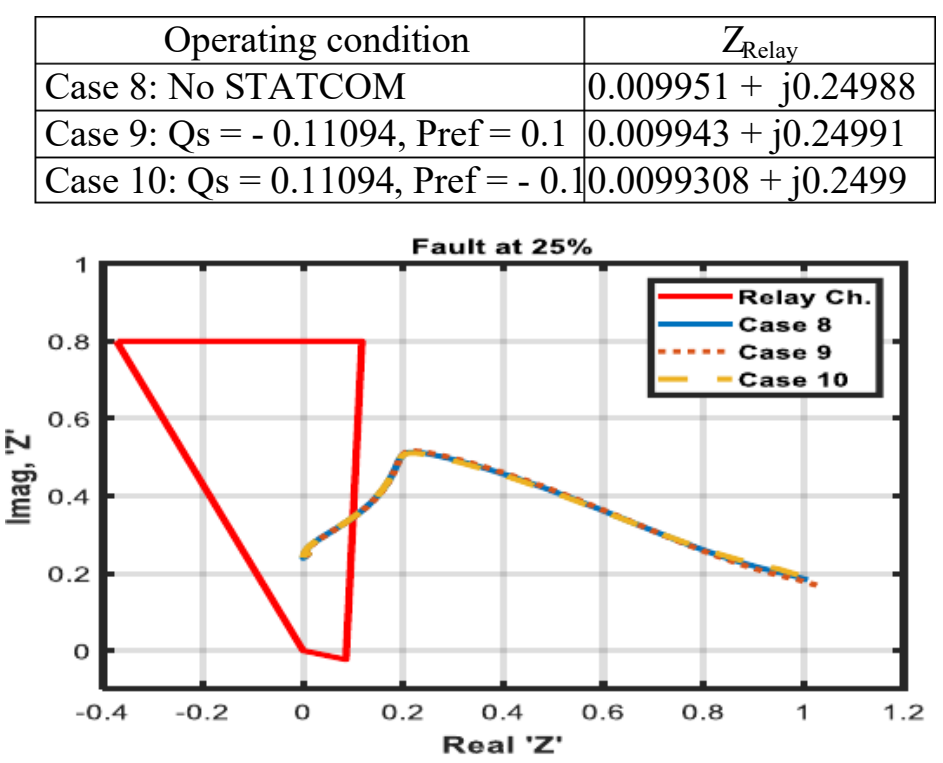

Figure $6 \mathrm{Z}_{\text {Rela }} \mathrm{y}$, Fault at 25\%

Table 2 shows the apparent impedance measured by the distance relay during bolted symmetrical fault at $25 \%$ for various operating modes of STATCOM - ES and Fig. 6 gives the obtained impedance plot and validates the result shown in table 2. It is concluded from Fig.6 and table 4 that the apparent impedance measured by the distance relay is independent of the operating mode of STATCOM, when STATCOM is outside the fault loop. It can also be seen from Fig. 6 that the relay operates correctly to clear the fault, since the fault is within the reach of relay.

\subsubsection{STATCOM in the fault loop}

In the case of faults beyond 50\%-line length, STATCOM - ES will be in the fault loop and hence emulated conductance and susceptance by STATCOM must be considered while computing the impedance seen by the distance relay. For a fault at a distance ' $x$ ' from relay location $(0.5<x \leq 1)$,

$Z_{\text {Relay }}=0.5 * Z_{L 1}+\frac{\left((1-x) * Z_{L 1}\right) * Z_{S T A T}}{\left((1-x) * Z_{L 1}\right)+Z_{S T A T}}$

\subsubsection{Reactive current injection alone}

Without STATCOM - ES, for a fault at $75 \%$-line length, impedance measured by the distance relay during fault is $0.75 * Z_{L 1}=(0.03+\mathrm{j} 0.75) \mathrm{pu}$. Table 3 shows the apparent impedance seen by the distance relay, when STATCOM - ES is operating in capacitive and inductive compensation modes and there is no real power exchange $(\mathrm{Qs}= \pm 0.16248$, Pref $=0)$. It can be observed from table 2 that with STATCOM operating in capacitive mode, resistance measured by the distance relay is decreased and reactance measured is increased. It is interesting to note that in the case of fault at $78 \%$ (case 12), reactance measured by the distance relay $(\mathrm{j} 0.8118 \mathrm{pu})$ is more than the set reactance $(\mathrm{j} 0.8 \mathrm{pu})$ and hence the relay under reaches and does not operate. It is validated from the impedance plot on $\mathrm{R}-\mathrm{X}$ plane shown in Fig.7. Similarly, when STATCOM is operating in inductive mode, resistance measured by the distance relay is increased and reactance measured is decreased. It is interesting to note that in the case of fault at $82 \%$ (case 14 ), reactance measured by the distance relay ( $0.78409 \mathrm{pu}$ ) is less than the set reactance $(\mathrm{j} 0.8 \mathrm{pu})$ and hence the relay over reaches and mal operates. It is validated from the impedance plot on $\mathrm{R}-\mathrm{X}$ plane shown in Fig.8. 
Impact of Real and Reactive Power Controllability of STATCOM on Transmission Line Protection

Table 3. Zrelay, STATCOM exchanging reactive power alone

\begin{tabular}{|l|c|c|}
\hline \multicolumn{1}{|c|}{ Operating condition } & \multicolumn{1}{|c|}{$\mathbf{Y}_{\text {STAT }}$} & \multicolumn{1}{c|}{$\mathbf{Z}_{\text {Relay }}$} \\
\hline $\begin{array}{l}\text { Case 11: Capacitive mode Fault at } \\
75 \%\end{array}$ & $-0.11964+\mathrm{j} 0.55396$ & $0.026094+\mathrm{j} 0.77762$ \\
\hline $\begin{array}{l}\text { Case 12: Capacitive mode Fault at } \\
78 \%\end{array}$ & $-0.1071+\mathrm{j} 0.50833$ & $0.026792+\mathrm{j} 0.8118$ \\
\hline Case 13:Inductive mode Fault at 75\% & $0.26873-\mathrm{j} 0.6536$ & $0.037606+\mathrm{j} 0.7231$ \\
\hline Case 14: Inductive mode Fault at $82 \%$ & $0.21083-\mathrm{j} 0.5379$ & $0.042398+\mathrm{j} 0.78409$ \\
\hline
\end{tabular}

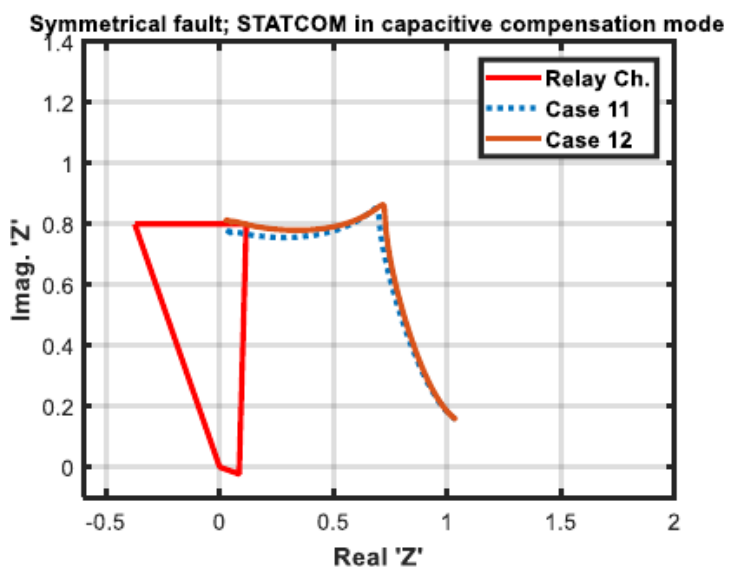

Figure 7 ZRelay, Capacitive mode

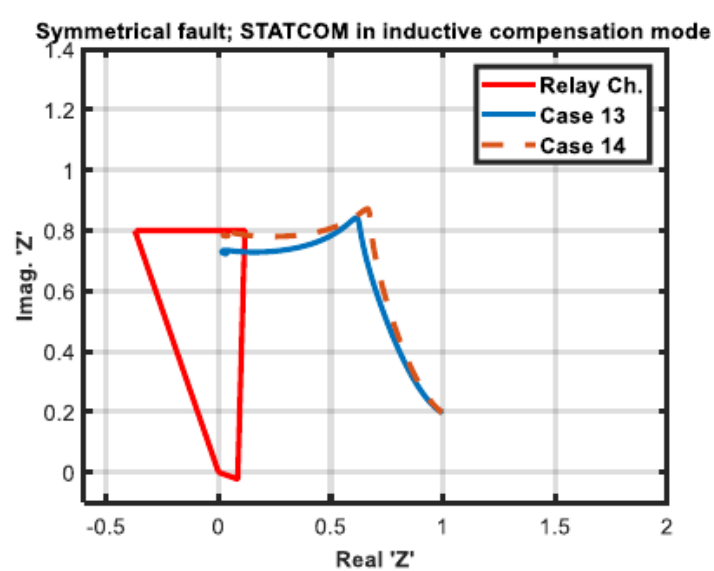

Figure 8 ZRelay, Inductive mode

\subsubsection{Real current injection alone}

Table 4 shows the apparent impedance seen by the distance relay, when STATCOM - ES is absorbing / supplying real power $\left(\mathrm{P}_{\text {ref }}= \pm 0.15\right)$ and there is no reactive power exchange $\left(\mathrm{Q}_{\mathrm{s}}\right.$ $=0)$. It is interesting to note that while exchanging real power alone, resistance reactance measured is only marginally decreased. It is also noted that while absorbing real power resistance measured by the distance relay is increased and resistance measured by the relay is decreased while supplying real power. It is interesting to note that, in the case of fault at $80 \%$ i.e. at the boundary of the reach of zone 1 relay unit (case 16 and case 18), reactance measured by the distance relay $(\mathrm{j} 0.79382 \mathrm{pu} / \mathrm{j} 0.79758 \mathrm{pu})$ is less than the set reactance $(\mathrm{j} 0.8$ $\mathrm{pu}$ ) and hence the relay operates correctly to clear the fault. Increase / decrease in resistance measured by the distance relay will not result in mal operation of the distance relay since the measured resistance is less than the set resistance which includes fault resistance in addition to line resistance. It is validated from the impedance plot on $\mathrm{R}-\mathrm{X}$ plane shown in Fig.9 and Fig. 10.

Table 4. $Z_{\text {Relay, }}$ STATCOM exchanging real power alone

\begin{tabular}{|c|c|c|}
\hline Operating condition & $\mathbf{Y}_{\text {STAT }}$ & $\mathbf{Z}_{\text {Relay }}$ \\
\hline Case 15: Qs $=0$, Pref $=0.15$ Fault at $75 \%$ & $0.67975+\mathrm{j} \quad 0.0197$ & $0.059305+\mathrm{j} 0.74514$ \\
\hline Case 16: $\mathrm{Qs}=0$, Pref $=0.15$ Fault at $80 \%$ & $0.59559+\mathrm{j} 0.02327$ & $0.069065+\mathrm{j} 0.79382$ \\
\hline $\begin{array}{c}\text { Case 17: Qs }=0, \text { Pref }=-0.15 ; \text { Fault at } \\
75 \%\end{array}$ & -0.619 -j 0.010299 & $0.0024375+\mathrm{j} 0.74858$ \\
\hline $\begin{array}{c}\text { Case 18: Qs }=0, \text { Pref }=-0.15 ; \text { Fault at } \\
80 \%\end{array}$ & $-0.54364-j \quad 0.01458$ & $-0.0027278+j 0.79758$ \\
\hline
\end{tabular}



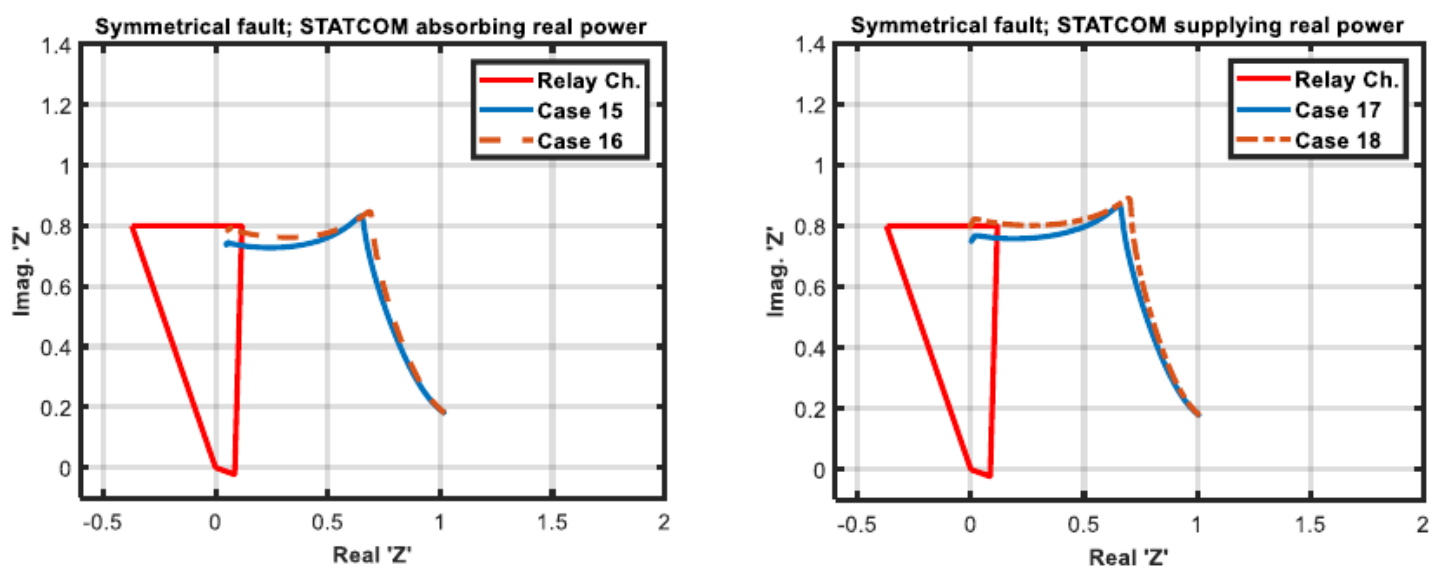

Figure 9, $Z_{\text {Relay }}$, STATCOM absorbing real power Figure 10, $Z_{\text {Relay }}$, STATCOM Supplying real power

\subsubsection{STATCOM simultaneously exchanging real and reactive power}

The impedance measured by the distance relay during fault, when STATCOM - ES operates in first quadrant (capacitive mode and absorbing real power, case 19 and 20) and third quadrant (inductive mode and supplying real power, case 21 and 22) is shown in table 5. It is very clear from table 5 that in the first quadrant operation of STATCOM - ES, resistance and reactance measured by the distance relay is increased.

Table 5. $Z_{\text {Relay }}$; STATCOM operation in first and third quadrant

\begin{tabular}{|l|c|c|}
\hline \multicolumn{1}{|c|}{ Operating mode } & Y $_{\text {STAT }}$ & Z $_{\text {Relav }}$ \\
\hline Case 19: Qs $=-0.11094$, Pref $=0.1 ;$ Fault at 75\% & $0.31527+\mathrm{j} 0.39621$ & $0.047547+\mathrm{j} 0.76629$ \\
\hline Case 20: Qs $=-0.11094$, Pref $=0.1 ;$ Fault at 78\% & $0.29284+\mathrm{j} 0.36528$ & $0.051717+\mathrm{j} 0.80018$ \\
\hline Case 21: Qs $=0.11094$, Pref $=-0.1$ Fault at 75\% & $-0.29069-\mathrm{j} 0.46646$ & $0.017516+\mathrm{j} 0.73103$ \\
\hline Case 22: Qs $=0.11094$, Pref $=-0.1$ Fault at $82 \%$ & $-0.25256-\mathrm{j} 0.39077$ & $0.015378+\mathrm{j} 0.79412$ \\
\hline
\end{tabular}

It can further be observed that in the case of fault at $78 \%$ (case 20 ), reactance measured by the distance relay $(\mathrm{j} 0.80018 \mathrm{pu})$ is slightly more than the set reactance $(\mathrm{j} 0.8 \mathrm{pu})$ and hence the relay under reaches and not operate for a fault within its reach. It can be observed from table 5 that in third quadrant of operation of STATCOM, resistance and reactance measured by the distance relay is decreased. It is interesting to note that in the case of fault at $82 \%$ (case 22 ), reactance measured by the distance relay $(\mathrm{j} 079412 \mathrm{pu})$ is slightly less than the set reactance $(\mathrm{j}$ $0.8 \mathrm{pu})$ and hence the relay over reaches and mal operates for a fault outside its reach. Results shown in table 5 are validated from the impedance plots on $\mathrm{R}-\mathrm{X}$ plane shown in Fig. 11 and Fig. 12 .

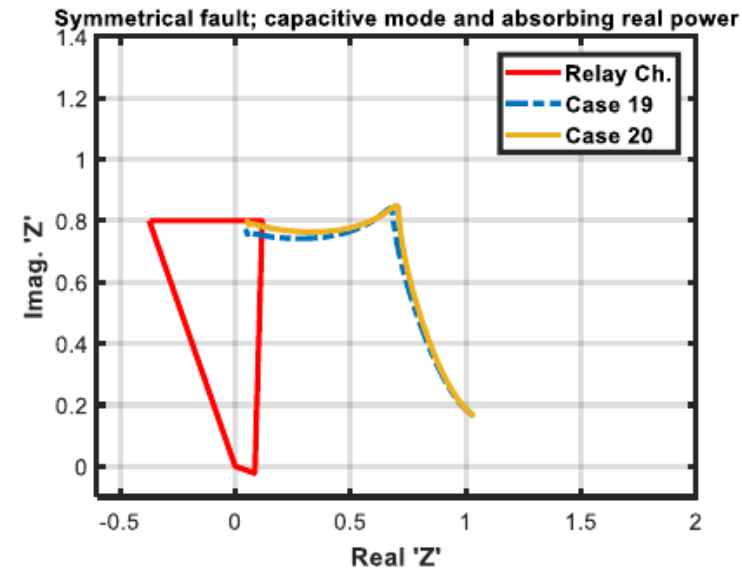

Figure $11 Z_{\text {Relay, }}$ operation in first quadrant

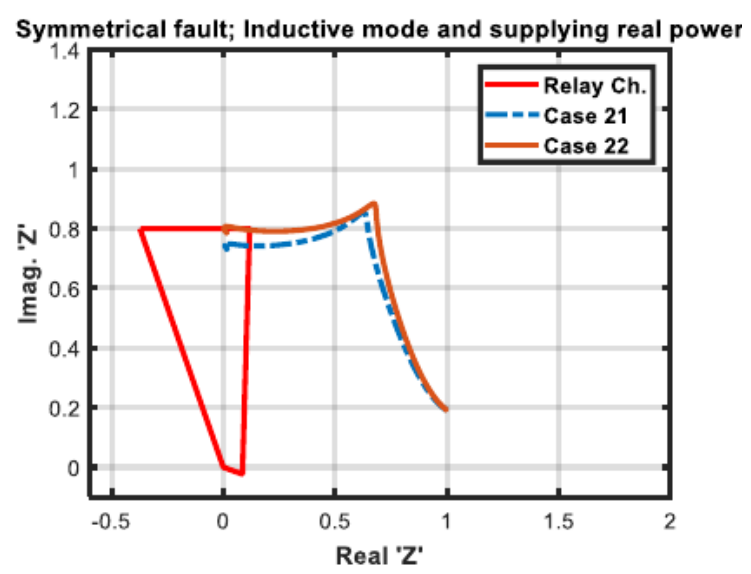

Figure $12 \mathrm{Z}_{\text {Relay, }}$ operation in third quadrant 


\subsection{Unsymmetrical Faults}

Impedance computation algorithm for distance relay is so implemented that distance relay will always measure positive sequence impedance up to the fault, irrespective of the type of the fault as given by equations 22 and 23 .

For LLG and LL faults involving R and Y phases,

$$
Z_{\text {Relay }}=\frac{V_{R}-V_{Y}}{I_{R^{-}} I_{Y}}
$$

In case of SLG fault involving R phase,

$$
Z_{\text {Relay }}=\frac{\mathrm{V}_{\mathrm{R}}}{\mathrm{I}_{\mathrm{R}}+\mathrm{m} * \mathrm{I}_{0}}
$$

where $I_{0}$ is the zero sequence component of current and ' $\mathrm{m}$ ' is the zero sequence compensation factor given by $\quad m=\frac{Z_{0}-Z_{1}}{Z_{1}}$

\subsubsection{STATCOM outside fault loop}

It is shown through simulation case studies in section 4.2.3 that for a given fault location, the impedance measured by the distance relay is independent of the operating mode of STATCOM - ES, when STATCOM is not in the fault loop. To analyze the impact of fault type on measured impedance, impedance seen by the distance relay is determined using equations 22 and 23 for unsymmetrical faults at $25 \%$-line length. STATCOM is considered to be operating in first quadrant. Results obtained are tabulated in table 6 and the obtained impedance plot on $\mathrm{R}-\mathrm{X}$ plane is shown in Fig.13.

Table 6. Fault at 25\%; Symmetrical and unsymmetrical faults

\begin{tabular}{|c|c|c|}
\hline $\begin{array}{c}\text { Operating } \\
\text { condition }\end{array}$ & Fault type & $\mathbf{Z}_{\text {Relay }}$ \\
\hline \multirow{2}{*}{$\begin{array}{l}\mathrm{Q} s=-0.11094, \\
\text { Pref }=0.1\end{array}$} & 3 phase fault & $0.0099566+\mathrm{j} 0.24993$ \\
\cline { 2 - 3 } & LLG fault & $0.0099137+\mathrm{j} 0.24995$ \\
\cline { 2 - 3 } & LL fault & $0.0099137+\mathrm{j} 0.24995$ \\
\cline { 2 - 3 } & LG fault & $0.0095232+\mathrm{j} 0.24924$ \\
\hline
\end{tabular}

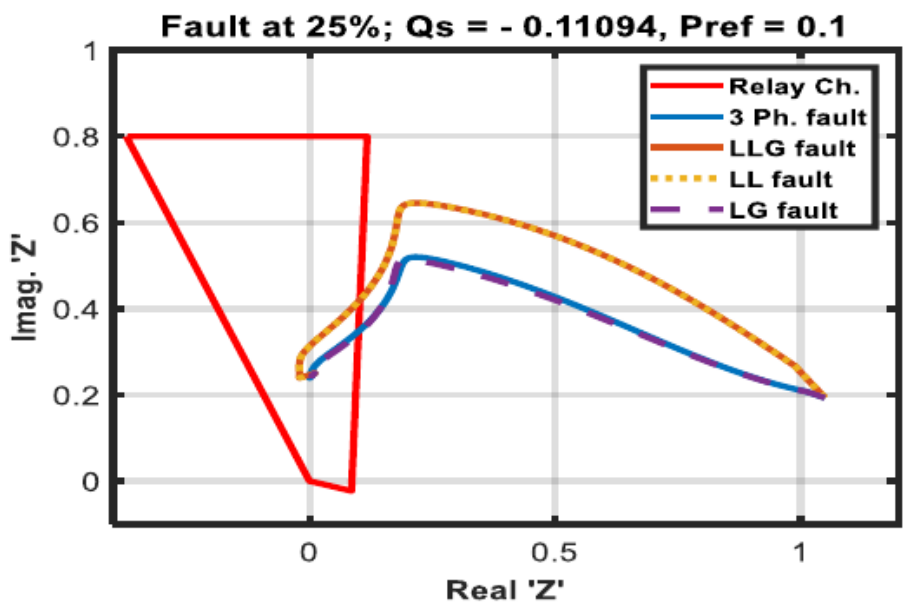

Figure 13 Symmetrical and unsymmetrical fault; STATCOM not in fault loop

It is very clear from table 6 that for a given fault location, measured impedance by the distance relay is almost independent of the fault type. Also from Fig.13, it can be seen that relay operates correctly, since Zrelay measured is inside the reach of zone 1 relay unit. 


\subsubsection{STATCOM in the fault loop}

Table 7 gives the impedance seen by distance relay in the case of symmetrical and unsymmetrical faults at 75\%-line length, with STATCOM - ES assumed to be operating in first quadrant.

Table 7. Fault at 75\%; Symmetrical and unsymmetrical faults

\begin{tabular}{|l|c|c|}
\hline $\begin{array}{c}\text { Operating } \\
\text { condition }\end{array}$ & Fault type & $\mathbf{Z}_{\text {Relay }}$ \\
\hline \multirow{2}{*}{$\begin{array}{l}\mathrm{Qs}=-11094, \\
\text { Pref }=0.1\end{array}$} & 3 phase fault & $0.04754+\mathrm{j} 0.7663$ \\
\cline { 2 - 3 } & LLG fault & $0.05025+\mathrm{j} 0.7633$ \\
\cline { 2 - 3 } & LL fault & $0.05331+\mathrm{j} 0.7558$ \\
\cline { 2 - 3 } & LG fault & $0.05168+\mathrm{j} 0.7559$ \\
\hline
\end{tabular}

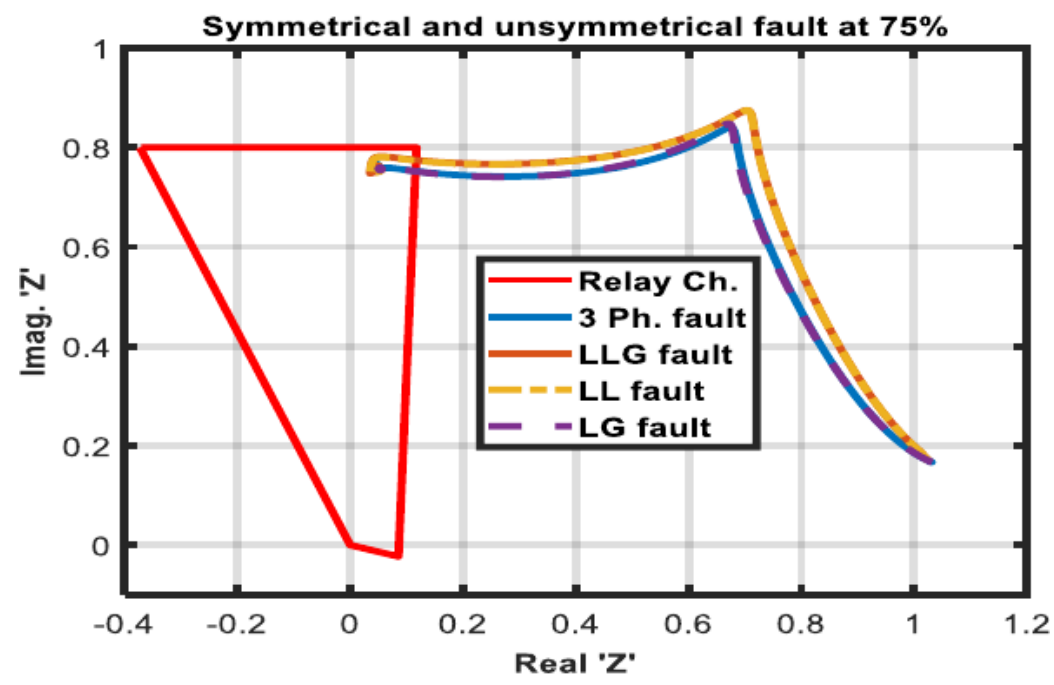

Figure 14 Symmetrical and unsymmetrical fault; STATCOM in the fault loop

It can be observed from table 7 that change in impedance seen by the distance relay is not significant with change in fault type. Fig. 14 shows the impedance plot obtained and validates the results shown in table 7. From impedance plots shown in Fig.13, and Fig. 14, it is concluded that for a given operating condition of STATCOM and fault location, impedance measured by the distance relay, is almost independent of the type of fault. Hence operation of the distance relay is not affected by fault type.

\subsection{Impact of fault resistance on distance relay operation}

In simulation case studies 8 to 22 , impact of emulated conductance and susceptance by STATCOM - ES on the performance of the distance relay is analyzed by considering bolted fault i.e. fault resistance is neglected. However, depending on the values of tower footing resistance, ground resistance and fault arc resistance, practically magnitude of fault resistance $\left(\mathrm{R}_{\mathrm{F}}\right)$ can be significant. Hence the measured impedance by distance relay will be different and may result in mal operation of the distance relay. It should be noted here that, in case of double feed faults, with bolted faults $\left(\mathrm{R}_{\mathrm{F}}=0 \Omega\right)$, impedance measured by the relay is dependent on the current flowing into the fault from one end only. However, when the value of $\mathrm{R}_{\mathrm{F}}$ is significant, impedance seen by the relay at each end of the line depends on the current fed to fault from the other end as well. 
In order to analyze the impact of fault resistance on the performance of distance relay, impedance seen by the distance relay is computed for a symmetrical fault at $75 \%$ with the following values of $\mathrm{R}_{\mathrm{F}}$. (a) $\mathrm{R}_{\mathrm{F}}=0 \Omega$ (b) $\mathrm{R}_{\mathrm{F}}=2 \Omega$ (c) $\mathrm{R}_{\mathrm{F}}=5 \Omega$. Operating mode of STATCOM is considered as absorbing real power and no reactive power exchange. Impedance measured by the relay is shown in table 8 .

Table $8 Z_{\text {Relay, }}$ Impact of fault resistance

\begin{tabular}{|l|c|c|c|}
\hline \multirow{2}{*}{ Operating condition } & \multicolumn{3}{|c|}{$Z_{\text {Relay }}$} \\
\cline { 2 - 4 } & $\mathrm{R}_{\mathrm{F}}=0 \Omega$ & $\mathrm{R}_{\mathrm{F}}=2 \Omega$ & $\mathrm{R}_{\mathrm{F}}=5 \Omega$ \\
\hline $\mathrm{Qs}=0$, Pref $=0.15$; Fault at $75 \%$ & $0.059305+\mathrm{j} 0.745$ & $0.016165+\mathrm{j} 0.808$ & $-0.044+\mathrm{j} 0.899$ \\
\hline
\end{tabular}

It is interesting to note from obtained values in table 8 that the resistance measured by the relay decreases significantly and reactance measured by the relay increases significantly with the increase in value of $R_{F}$. It is also observed that relay under reaches and does not operate when $\mathrm{R}_{\mathrm{F}}=5 \Omega$. Results shown in table 8 is validated through impedance plot in $\mathrm{R}-\mathrm{X}$ plane shown in Fig.15.

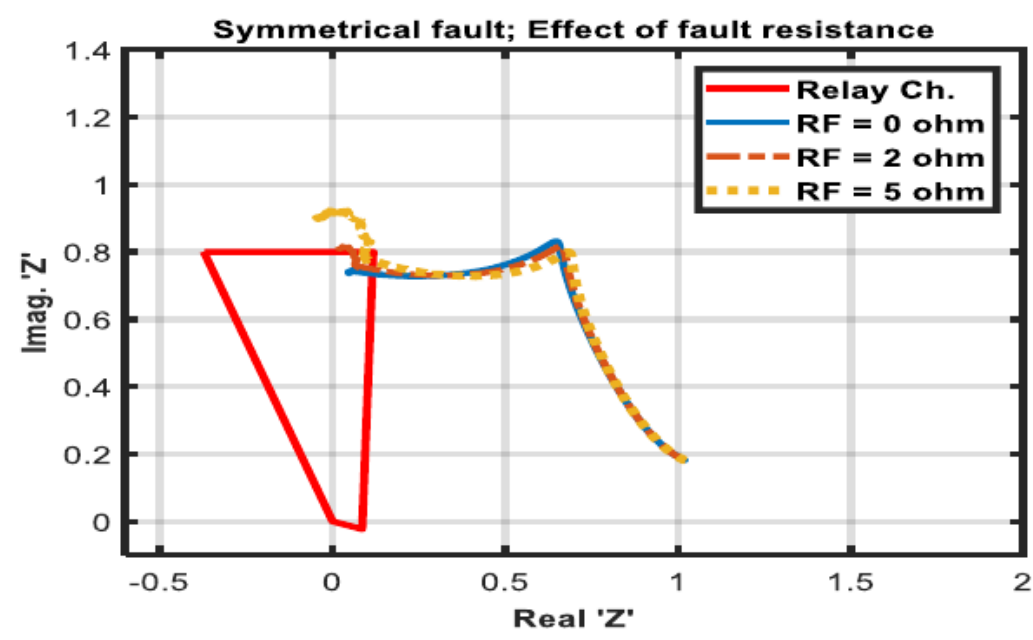

Figure 15 Impact of fault resistance, Fault at 75\%, STATCOM absorbing real power

\subsection{Discussion}

Inference from the results obtained through various case studies carried out are,

- STATCOM emulates positive conductance while absorbing real power and emulates positive susceptance in capacitive mode of operation.

- Under normal (no fault) condition, distance relay will not operate when STATCOM is operated with in its ratings.

- Constant reactive current control and dynamically changing real power reference value for real power controller of STATCOM prevents damage to STATCOM during fault.

- When STATCOM is outside fault loop (faults up to 50\%-line length), measured impedance by distance relay is independent of operating mode of STATCOM.

- When STATCOM - ES is within the fault loop (faults beyond 50\%-line length), impedance seen by distance relay depends on the operating mode of STATCOM - ES.

- Relay under reaches in case of capacitive mode and over reaches in case of inductive mode of operation of STATCOM. 
- When STATCOM - ES is exchanging real power alone, chances of mal operation of distance relay is very less.

- For a given operating mode of STATCOM and fault location, apparent impedance seen by the distance relay is independent of the type of fault (symmetrical or unsymmetrical).

- Since STATCOM is a shunt connected device, change in impedance seen by the distance relay is not significant and hence the extent of over reach or under reach is about $2 \%$ in case of bolted faults.

- Possibility of mal operation of distance relay is increased with the increase in the value of fault resistance.

\section{CONCLUSION}

In this paper, impact of emulated conductance and susceptance by a STACOM incorporating an energy storage device on the performance of a distance relay is discussed in detail. Operation of STATCOM in all the four quadrants of P - Q plane is considered. Details of the new control strategy proposed to dynamically change the reference value for real power exchange by STATCOM to avoid damage to STATCOM during fault is discussed. It is clearly shown that when STATCOM is outside the fault loop, operating mode and type of fault does not influence the impedance seen by the distance relay. When STATCOM is inside the fault loop, it is demonstrated through various case studies that the distance relay under reaches when STATCOM is operating in capacitive mode and over reaches in case of inductive mode. It is also shown that impact of real power exchange by STATCOM on the apparent impedance seen by the distance relay is negligible. However, with the increase in the value of fault resistance, it is shown that the chances of mal operation of distance relay is increased.

\section{REFERENCES}

[1] K.R. Padiyar, FACTS controllers in Power transmission and Distribution, New Age International, 2008.

[2] N.G. Hingorani and L. Gyugyi, Understanding FACTS. New York: IEEE press, 2000.

[3] K.R. Padiyar and Nagesh Prabhu "Design and Performance Evaluation of Sub Synchronous Damping Controller with STATCOM", IEEE Transactions on Power Delivery, Vol. 21, NO. 3, July 2006

[4] Ravindra P. Singh, Digital Power System Protection, PHI, 2007.

[5] M. Purohit, V.N. Gohokar, "Effects of series compensation on distance protection of high voltage transmission lines under fault conditions", International Journal of Electrical Engineering \& Technology (IJEET) Volume 9, Issue 6, November-December 2018, pp. 57-66

[6] P.K. Dash, A.K. Pradhan, G. Panda and A.C. Liew, "Digital Protection of Power transmission lines in the presence of series compensated FACTS devices", in Proc., IEEE Power Engineering Society, Winter meeting, Vol.3, pp. 1967 - 1972, 2000

[7] Khalil El - Aroundi, Geza Joos and Donald T. McGills, "Operation of impedance protection relays with the STATCOM, IEEE transactions on Power delivery, Vol.17, No.2, pp.381 - 387, April 2002.

[8] T.S. Sidhu, R.K. Varma, "Performance of Distance relay on Shunt FACTS compensated Transmission Lines", IEEE Transactions on Power delivery, Vol.20, No.34, July 2005.

[9] Fadhel A, T.S. Sidhu, R.K. Varma, "Performance comparision of Distance protection schemes for Shunt FACTS compensated Transmission lines", IEEE transactions on Power delivery, vol.22, no.4, October 2007.

[10] A. H. Mohammadzadeh, I. Dabhagiyan Amiri, "The impact of shunt FACTS devices on distance relay performance", 2nd IEEE International Conference on Knowledge-Based Engineering and Innovation (KBEI), November 2015 
[11] P.K. Dash, A.K. Pradhan, G. Panda and A.C. Liew," Adaptive relay setting for FACTS", IEEE transaction on Power delivery, vol.15, no.1, pp.38 - 43, Jan 2000.

[12] Sham M V, Chethan K S and K P Vittal," Development of Adaptive Distance Relay for STATCOM Connected Transmission Line”, 2011 IEEE PES Innovative Smart Grid Technologies - India

[13] Martin Cruz, Rodriguez Paz, Roberto Chouty and Arturo Suman Bretas, "Adaptive ground distance protection for UPFC compensated transmission lines: A formulation considering the fault resistance effect", International journal of electrical power and energy systems, pp.124-131, May 2015.

[14] Mebtu Beza, Massimo Bongiorno "An adaptive Power Oscillation Damping Controller by STATCOM with Energy Storage”, IEEE Trans. Power sys. pp .484 -493, Jan.2015.

[15] L. Zhang, M.L. Crow, Z. Yang, S. Chen, "The steady state characteristics of an SSSC integrated with energy storage" in proc. Power engineering society winter meeting, vol.3, IEEE 2001.

[16] Zhiping Yang, M.L. Crow, Chen Shen, Lingli Zhang, "The steady state characteristics of a STATCOM integrated with energy storage"”, in proc. IEEE Power engineering society summer meeting, July 2000.

[17] M. Stella, Morris A.G. Ezra, A. Peer Fathima, C. Khang Jiunn, "Research on the efficacy of unified STATCOM-Fuel cells in improving the transient stability of power systems", International Journal of hydrogen energy, 2016.

[18] A. Kazemi, S. Jamali and H. Shateri, "Effects of SMES Equipped SSSC on Distance Relay Tripping Characteristic", Transmission and Distribution Conference and Exposition, 2008, IEEE/PES, April 2008.

[19] S. Jamali, A. Kazemi and H. Shateri, "Effect of SMES Equipped UPFC on Distance Relay Tripping Characteristic", Power System Technology and IEEE Power India Conference, 2008. POWERCON 2008.

[20] R.C. Mala, Nagesh Prabhu and H.V. Gururaja Rao, "Performance of STATCOM - ES in mitigating SSR", International Journal of Power Electronics and Drive Systems", Vol. 8, No. 4, December 2017, pp. 1822 1829.

\section{APPENDIX}

Test system is adapted from IEEE first benchmark model

System Data (All values in pu; Base MVA $=892.4$, Base Voltage $=500 \mathrm{KV}$ ).

\section{Generator data}

$\mathrm{Ra}=0 ; \mathrm{X}_{\mathrm{d}}=1.79 ; \mathrm{X}_{\mathrm{q}}=1.71 ; \mathrm{X}_{\mathrm{d}}{ }^{\prime}=0.169 ; \mathrm{X}_{d}^{\prime \prime}=0.135 ; \mathrm{Xq}^{\prime}=0.228 ; \mathrm{X}_{\mathrm{q}}{ }^{\prime \prime}=0.2 ; \mathrm{T}_{\mathrm{d}}{ }^{\prime}=0.4 ; \mathrm{T}_{\mathrm{d}}{ }^{\prime \prime}=$ $0.0259 ; \mathrm{T}_{\mathrm{q}}{ }^{\prime}=0.1073 ; \mathrm{T}_{\mathrm{q}}{ }^{\prime \prime}=0.0463 ; \mathrm{f}=60 ; \mathrm{H}=5 ; \mathrm{D}=0$;

\section{Transmission system data}

$\mathrm{R}_{\mathrm{t}}=0.0 ; \mathrm{X}_{\mathrm{t}}=0.14 ; \mathrm{R}_{\mathrm{L}}=0.04 ; \mathrm{X}_{\mathrm{L}}=1 ; \mathrm{Xc}=0.45 ; \mathrm{X}_{\text {sys }}=0.06 ; \mathrm{V}_{\mathrm{g}}=\mathrm{V}_{\mathrm{g}} \angle \theta ; \mathrm{E}_{\mathrm{b}}=1 \angle 0 ;$

STATCOM data: $150 M V A ; \mathrm{R}_{\mathrm{s}}=0.01 ; \mathrm{X}_{\mathrm{s}}=0.15 ; \mathrm{V}_{\mathrm{dc}}=0.7$ 